\title{
DIGITAL TRIBALISM AND THE INTERNET OF THINGS: CHALLENGES AND OPPORTUNITIES
}

\author{
AJ Grant, Robert Morris University, granta@rmu.edu
}

\begin{abstract}
A number of scholars have begun to research the existence of "digital tribes" appearing on the internet, suggesting that internet users are, in fact, divided and splintered into a variety of digital tribes. This paper explores the challenges created by digital tribalism and the tribes' connections to the IoT, as well as the opportunities afforded, and includes the results of two online tribal surveys taken by students in a leadership and popular culture class in Spring 2020.
\end{abstract}

Keywords: Digital Tribes, Generation Z, Generation Y, The Internet of Things, Conspiracy theories.

\section{INTRODUCTION}

The Internet of Things (IoT) poses a set of challenges and opportunities for educators, market research organizations and businesses as an array of smart devices connected to each other and to the Internet operate and communicate apart from human intervention and agency. The challenges and opportunities become increasingly apparent against the backdrop of deepening political, economic and social factions in the United States and throughout the world, partially engendered by the proliferation of social media. Recently, a number of scholars have begun to research the existence of "digital tribes" appearing on the internet, especially Facebook, Instagram and Twitter, suggesting that internet users are, in fact, divided and splintered into a variety of digital tribes. This paper explores the challenges created by digital tribalism and the tribes' connections to the IoT, as well as the opportunities afforded, and includes the results of two online tribal surveys taken by students in a leadership and popular culture class in Spring 2020.

\section{LITERATURE REVIEW: DIGITAL TRIBES AND THE IOT}

In a recent survey of research on the Internet of Things (IoT), Eugene Siow, Thanassis Tiropanis and Wendy Hall identified "four principles" that were "well defined" in the IoT literature:

(1) The IoT exists at a global scale,

(2) consists of uniquely identifiable Things with sensing or actuating capabilities linked to the physical world,

(3) which are interconnected by existing or future technologies so that data can be shared,

(4) and have potential for societal impact through advanced services. (2018, p. 5)

These four principles of the IoT depict an interconnected world of people and smart technologies, in which our current undergraduate students are thoroughly enmeshed. These students (age 18-24) are mostly members of Generation Z (Gen Z, born 1995-2012), though we might have an occasional Gen Y, aka Millennials (born 1981-1996) and once in a while a Gen Xer (born 1961-1980), but rarely a Boomer (born 1946-1964). If most of our undergraduate students are members of Gen $\mathrm{Z}$ then we know that they are also digital natives, having known only a world with home computers, the Internet and mobile phones. Most of these digital natives are actively engaged with the Internet and are certainly candidates for membership in what many are calling digital tribes.

Mihai Burlacu (2014) defines digital tribes based on four "dimensions," which include "people, purposes, protocols and technology" and concludes that "[e]lectronic tribes include members that have common objectives. They interact with each other according to clearly defined protocols and roles using Internet technologies that support online sociability" (p. 242). With the problems of time and space pretty much relativized, these tribes are in the process of redefining human communication and creating virtual cultures similar to "real" cultures: "In a sense these "virtual cultures' seem more real," Burlacu argues, "because they epitomize the symbolic dimension of human existence" and can be compared to "Plato's World of Ideas" (p. 243), which are ontologically and epistemologically prior to and foundational for the sensible world, which is a pale imitation of the Ideal Forms. Burlacu concludes that we have moved beyond simulation in these digital tribes and that these tribes now stand in for the original (p. 246), and have, 
in fact, replaced it. I would add that the Coronavirus Pandemic has only reinforced and further reified, through social distancing and sheltering in place, the viability of these tribes and their deepening reliance on and connection to the IoT.

Burlacu's speculation is fascinating and may be true, but how do we even know these tribes exist in cyber space? A number of large studies conducted over the past ten years have attempted to identify and describe these tribes. The Digital Anthropology Report of 2009 surveyed 2000 UK "users of technology" and identified six tribes, which are described in terms of internet usage and relative savvy:

- Digital extroverts (9\%*): Unsurprisingly, these are the early adopters, or advanced users of technology

- Timid technophobes (23\%): People with limited technology skills, who are generally suspicious of all things digital

- Social secretaries (13\%): Those who use technology particularly for social means and ends

- First lifers (12\%): Those who are neither for or against technology per se, and will only use a few applications that they find particularly useful

- E-ager beavers (29\%): Those who use technology a lot, but are less confident in creating digital artefacts than the digital extroverts

- Web boomers (8\%): An older group of Internet users who mainly use the Internet to access information online [* percentages refer to the numbers of survey participants who made up each 'tribe'] (Hockly, 2011, para 4)

While these findings are interesting, they are not particularly relevant for this study, because the study is eleven years old and all of my students have mobile phones loaded with apps, which they are adept at using and seem bent on using in class.

In 2017 a Canadian research firm, Environics Research, administered a survey of Millennials, which is still collecting data online at https://environicsresearch.com/insights/meet-millennials/. Bradley Cooper describes the six (Canadian) millennial tribes identified in this research as follows:

- Lone Wolves tend to live alone and closely mirror Gen Xers' desire for independence. They usually have a "live and let live" attitude.

- Engaged Idealists wish to engage in meaningful careers. They want to contribute as much as possible to their work, environment and communities. 70 percent are women and 45 percent are single women.

- Bros and Brittanys work hard and play harder. They like to be on top of fashion and technology trends and tend to have more defined gender roles. They represent one-quarter of Canadian millennials.

- Diverse Strivers long to be successful in many ways and value respect and status. They are the most likely to have a household income of six figures or more. They also happen to be big spenders.

- Critical Counterculturalists tend to be progressive-minded. They value diversity and gender equality, and heavily oppose what they view as illegitimate or superficial status and authority. They long for authentic relationships. Almost half are single men and 83 percent have no religion.

- New Traditionalists tend to be more religious than other tribes; 61 percent espouse conservative Protestantism. They are more likely to be married and tend to respect authority more than millennials. They value duty and some traditional values, but they are also environmentally conscious and often purchase green products. (2017, para 3).

These categories provide a richer, fuller description of these "tribes," which might be useful for marketing people developing advertisements, businesses developing products, and political campaigns seeking to influence voters.

Hawkins et al. (2018) more recently conducted a large scale survey of U.S. citizens for More in Common, a public interest group, and produced a report entitled "Hidden Tribes: A Study of America’s Polarized Landscape" and developed the following typology of tribes: 
- Progressive Activists: younger, highly engaged, secular, cosmopolitan, angry.

- Traditional Liberals: older, retired, open to compromise, rational, cautious.

- Passive Liberals: unhappy, insecure, distrustful, disillusioned.

- Politically Disengaged: young, low income, distrustful, detached, patriotic, conspiratorial.

- Moderates: engaged, civic-minded, middle-of-the-road, pessimistic, Protestant.

- Traditional Conservatives: religious, middle class, patriotic, moralistic.

- Devoted Conservatives: white, retired, highly engaged, uncompromising, patriotic. (p. 7)

The list needs to be read from top to bottom and understood as a movement from left to right "in terms of the ideological spectrum" (p. 7). Hawkins et al. argue that this tribal segmentation holds for a wide variety of issues including views of gender, race, religion and sexuality and are illustrative of "core beliefs." In addition, the researchers claim that these tribes better describe potential political beliefs than more traditional groupings of people:

Further evidence of the relevance of core beliefs and their associated tribal identities is that tribal membership predicts differences in Americans' views on various political issues better than demographic, ideological, and partisan groupings. This can be seen on subjects such as approval of President Trump, Deferred Action for Childhood Arrivals (DACA), and approval of the modern feminist agenda. On these questions and many others, the differences between the most ideological segments are greater than the differences between, for instance, self-described "strong Republicans" and "strong Democrats.” (p. 7)

These categories make sense to me and ring true, since I have encountered students who exhibit the core beliefs across this spectrum and express them in the ethics, communication and popular culture courses I teach. If our students (and we) are this polarized, how can we possibly connect with them? Regardless of what we teach or where we teach we have to introduce our tribalized students to what is true in our fields of study (epistemologies) and also explain what is real (ontologies), whether we teach English, Information Systems, or ethics. I should qualify this further-we have to equip our students to learn how to discern truth as opposed to falsehood and reality as opposed to fabrication. This is no small task, especially if the online world and the IOT are perceived and experienced as Platonic Ideals, as opposed to the shabby empirical world of the five senses. And this will involve the debunking of false narratives and conspiracy theories spun out and gone viral on the Internet as well. I received the following statements from "Bob" (pseudonym) in an "Ethical Will" assignment I had students do for an undergraduate course in leadership and ethics in Fall 2019:

The ethics I would like to see people live by here in our great country the United States of America and the ones I believe are accepted as unethical are first and foremost; to love this country and respect the flag. It doesn't matter if we evade [sic] other countries and force capitalism on them, after all, we do it for a greater good. It is ethical for the citizens of this country to support the government in forcing our way of living on other countries. The people should instill this ethic in their children since they are young, so that they never or will likely, never question the authority or schools helping enforce patriotism. Many other countries even obligate their subjects to honor the territories they are born in, why shouldn't we be able to force it on our children for our own protection. We may never have a clear answer from our government, but we live better than the rest of the masses on this planet. And to question our government is unethical, as they may have secrets for national security.

Second, I would like to say that God is no joke, and he is a vengeful messiah, and it is only ethical to believe in him, and immoral to not believe in him or to be agnostic, or to affiliate with any religion that believes in more than one deity. Many countries have their divinity but, in this country, we should all believe in Jesus Christ as our Lord and Savior. More specific would be best to be a devout Catholic, as its history of crusades and inquisition was for the glory of God, and although maybe we should not allow that to happen again, it was the past, and we learned from it, and possibly took out many other rival religions with the purges. Remember, the highest person on earth is the Pope, and he would not practice anything sinister or wrong, as the church is the epidemy [sic] of the word of Christ and his benevolence. 


\section{Issues in Information Systems}

Volume 21, Issue 2, pp. 213-220, 2020

A third major ethical behavior we should have is to the police. They have the power, and they should have the power; to be able to do whatever they want. You should let them question you and society should let them misbehave when they want to, because after all, they do it for the best interest of society and there is no real abuse going on. They make mistakes just like any other human, and to believe, the people or individuals that are hired to uphold the law are actually abusing their power or have no idea of basic human rights is preposterous. For example: they do not know who they are stopping when pulling a vehicle over, so it is natural that they are trained to be suspicious and treat everybody as a criminal, after all they are practicing self-preservation, and in the process of making laws, we should lose some of our rights so that we can have more security.

This is, admittedly, an extreme example, but where does one begin with the debunking? How do I engender trust with this student? As a member of the Traditional Liberal Tribe, I am now face to face with a student who is, in all probability, a member of the Devoted Conservative Tribe with obvious White Supremacist leanings. He believes that all Americans should be Catholic, that the Crusades and the Inquisition were justified, that it's fine to invade other countries and "force capitalism" on them, that we should never question authority, and that police brutality either doesn't exist or doesn't matter. This student was enrolled in my hybrid leadership and ethics class, which required a number of oral presentations, but he requested on the first day of class that he not have to give them, because of a great fear of public speaking. I acquiesced, not realizing that letting him off the hook on oral presentations increased his isolation and gave him permission to dominate the online discussions, often ridiculing the ethical positions of Aristotle, Kant, and Mill, but saving his most vicious attacks for Benedict and Rand, and regularly attacking my online posts.

But debunking isolated, tribalized students is not that simple, especially if they are isolated from other students. Fabiana Zollo et al. (2017) did a quantitative analysis of 54 million Facebook users in order to study how they “consume scientific and conspiracy-like contents” (p. 2) and they focused largely on the issue of content verification:

Indeed, it is easy for scientific news to identify the authors of the study, the

university under which the study took place and if the paper underwent a peer review process. On the other hand, conspiracy-like content is difficult to verify because it is inherently based upon suspect information and is derived [from] allegations and a belief in secrets [being withheld] from the public. The self-description of many conspiracy pages on Facebook, indeed, claims [sic] that they inform people about topics neglected by mainstream media and science. Pages like I don't trust the government, Awakening America, or Awakened Citizen, promote wide-ranging content from [topics such as] aliens, chem-trails, to the causal relation between vaccinations and autism or homosexuality. Conversely, science news pages--e.g. Science, Science Daily, Nature--are active in diffusing posts about the most recent scientific advances. (2017, p. 2)

Zollo et al. found that "two well-formed and highly segregated communities exist around conspiracy and scientific topics-i.e., users are mainly active in only one category” (p. 2), forming two separate echo chambers (and tribes). In order to test the degree to which confirmation bias was present in these two groups, they selected 50,220 debunking posts, mainly in the science echo chamber and found that "the majority of likes on debunking posts is left by users polarized towards science $(* 67 \%)$, while only a small minority $(* 7 \%)$ by users polarized towards conspiracy. However, independently of the echo chamber, the sentiment expressed by users when commenting on debunking posts is mainly negative” (2017, p. 2). In short, people who read and like conspiracy theories don't like to have them debunked (only 7\% "liked" the debunking), but the majority of those following science news (67\%) "liked" the debunking, welcomed the correction provided, presumably by experts.

Back to Bob. I have been teaching at the college level for 44 years and Bob, believe it or not, was a new experience for me. He suffered through the classroom experience of the leadership and ethics course, silent, grim and glaring at me throughout each class. In the class I explain that while I value religion, ethics cannot be taught from a particular religious point of view, since my university is a private secular university. This is why I cover virtue ethics, deontology, utilitarianism, ethical egoism and ethical relativism, encouraging students to develop an ethical stance appropriate for the diverse workplaces where they will find themselves. I teach the "truth" of these ethical systems and engage students to think about their actual experience with others at school and in their workplaces (their realities). In the online part of the class I called Bob out when he engaged in logical fallacies by attacking people's character 
(argumentum ad hominem), when he beat up on me or others (ad bacculum), forcing him to stick to the strength of his arguments and provide evidence for them, but I did not and could not (I thought) attack his worldview, however defective and dangerous it might have been.

\section{METHODOLOGY/RESULTS: THE TRIBAL SURVEYS}

Because of a growing interest in online tribes, the following semester I had students take the Environics Research survey of Millennials during the first week of my eight week Leadership and Popular Culture class in Spring 2020 (https://environicsresearch.com/insights/meet-millennials/). Twenty-two of twenty-three students took the survey (22/23) and submitted their results to me (below). Each student confirmed, after reading descriptions of all the categories, that this was indeed a good fit for her or him. Incidentally, the university shut down after the first week and we moved all of our courses to a fully online format with asynchronous and synchronous discussions and classes.

Table 1. Digital Tribe Affiliation

\begin{tabular}{|l|l|}
\hline DIGITAL TRIBE AFFILIATION according to the Environics Research Survey & $\begin{array}{l}\text { Number of students } \\
\text { (N=22) }\end{array}$ \\
\hline $\begin{array}{l}\text { Lone Wolves tend to live alone and closely mirror Gen Xers' desire for independence. } \\
\text { They usually have a "live and let live" attitude. }\end{array}$ & 0 \\
\hline $\begin{array}{l}\text { Engaged Idealists wish to engage in meaningful careers. They want to contribute as } \\
\text { much as possible to their work, environment and communities. 70 percent are women } \\
\text { and } 45 \text { percent are single women. }\end{array}$ & 3 \\
\hline $\begin{array}{l}\text { Bros and Brittanys work hard and play harder. They like to be on top of fashion and } \\
\text { technology trends and tend to have more defined gender roles. They represent one- } \\
\text { quarter of Canadian millennials. }\end{array}$ & 6 \\
\hline $\begin{array}{l}\text { Diverse Strivers long to be successful in many ways and value respect and status. } \\
\text { They are the most likely to have a household income of six figures or more. They also } \\
\text { happen to be big spenders. }\end{array}$ & 9 \\
\hline $\begin{array}{l}\text { Critical Counterculturalists tend to be progressive-minded. They value diversity } \\
\text { and gender equality, and heavily oppose what they view as illegitimate or } \\
\text { superficial status and authority. They long for authentic relationships. Almost half are } \\
\text { single men and 83 percent have no religion. }\end{array}$ & 0 \\
\hline $\begin{array}{l}\text { New Traditionalists tend to be more religious than other tribes; 61 } \\
\text { percent espouse conservative Protestantism. They are more likely to be married and } \\
\text { tend to respect authority more than millennials. They value duty and some traditional } \\
\text { values, but they are also environmentally conscious and often purchase green } \\
\text { products. (2017, para 3). }\end{array}$ & 4 \\
\hline
\end{tabular}

Results for the Environics Research Survey of Millennials collected in my Leadership and Popular Culture class in March 2020.(https://environicsresearch.com/insights/meet-millennials/)

Although the Environics Survey was designed for Millennials I thought it would be interesting to see the tribal affiliations of the students in this class, all of whom were members of Generation Z (Gen Z, born 1995-2012, age 1824). Nine of the twenty-two students were identified as Diverse Strivers and six as Bros and Britannys, which constituted $70 \%$ of the responses. Both of these groups clearly value success in their endeavors and long for status, respect and large incomes. Three students were identified as Engaged Idealists who show concern for contributing meaningfully to their workplaces, communities and the environment. Four students were identified as New Traditionalists, closely aligned with conservative religious groups and traditional values. None of the students were identified as either Lone Wolves or Critical Counterculturalists.

I had the same students take the Hawkins et al. (2018) survey "Hidden Tribes: A Study of America's Polarized Landscape" during the last week of class in Spring 2020. All twenty-two students shared their results with me (22/22); one student had dropped the course by the final week. Each student confirmed in writing, after reading descriptions of all the categories, that this was indeed a good fit for her or him. 
Table 2. Digital Tribe Affiliation

\begin{tabular}{|l|l|}
\hline Tribal Affiliation & $\begin{array}{l}\text { Number of Students } \\
\text { (N=22) }\end{array}$ \\
\hline Progressive Activists: younger, highly engaged, secular, cosmopolitan, angry. & 2 \\
\hline Traditional Liberals: older, retired, open to compromise, rational, cautious. & 3 \\
\hline Passive Liberals: unhappy, insecure, distrustful, disillusioned. & 3 \\
\hline $\begin{array}{l}\text { Politically Disengaged: young, low income, distrustful, detached, patriotic, } \\
\text { conspiratorial. }\end{array}$ & 6 \\
\hline Moderates: engaged, civic-minded, middle-of-the-road, pessimistic, Protestant. & 5 \\
\hline Traditional Conservatives: religious, middle class, patriotic, moralistic. & 3 \\
\hline $\begin{array}{l}\text { Devoted Conservatives: white, retired, highly engaged, uncompromising, patriotic. } \\
\text { (p. 7) }\end{array}$ & 0 \\
\hline
\end{tabular}

Results for the Hawkins et al. (2018) survey “Hidden Tribes: A Study of America's Polarized Landscape” collected during the last week of class in April 2020.

While the Environics survey looked primarily at lifestyles and vocational aspirations, the Hidden Tribes survey attempted to identify political orientation so that as one moves down the table one is actually moving from left to right politically. It is interesting to note, however, that as with the Environics survey there is a cluster of twelve responses in the middle, constituting $54 \%$ of the participants, who were identified as either politically disengaged or moderate. Eight of the students fell into the three left leaning categories of progressive activists, traditional or passive liberals, and three students identified as traditional conservatives while none of them were identified as devoted conservatives.

\section{DISCUSSION}

The online discussions (both synchronic and asynchronic) students had about tribal affiliation were fascinating and rich, and provided a nice way for students to introduce themselves. The first day of class most of the students arrived with their Environics tribal affiliation, so I had them stand with their tribes (four tribes identified) and talk about what it felt like to be identified with this particular tribe. Most of the students agreed that they were associated through the survey with the appropriate tribe-Engaged Idealists, Bros and Brittanys, Diverse Strivers, or Engaged Idealists—and that they tended to relate to and socialize with people who shared these values. Indeed, a number of students who took the class already knew and associated with other students who were in their tribe. Two of the Black male Bros and Brittany's said they felt they actually belonged to the Diverse Strivers and wanted to move to that tribe. I asked why and they laughed and pointed to the five Black male students in the Diverse Strivers, all of whom were athletes, like them. I then had each student introduce herself/himself to the rest of the class providing their name and what they expected to get out of a class on Leadership and Popular Culture.

By the time students took the "Hidden Tribes" survey in the last week of the class, the class had been conducted online for seven weeks, because of the Pandemic. The prompt I provided for students for the final online discussion of tribes was as follows: "Go to https://hiddentribes.us/ and take the quiz, then in three paragraphs, reflect on which "tribe" you belong to, what your core values are, and how they will guide you in the upcoming presidential election.” As noted above, there is a cluster of eleven responses in the middle, constituting $50 \%$ of the participants, who were identified as either politically disengaged or moderate. Nine of the students fell into the three left leaning categories of progressive activists, traditional or passive liberals, and three students identified as traditional conservatives while none of them were identified as devoted conservatives. But, unlike the first survey, this survey engendered a good deal of discussion about the identified tribal affiliations.

Twenty-one (21/22) students participated in the discussion. Fourteen of them confirmed that the survey had put them in the correct tribe. Seven students had a Yes/But response, noting that they probably fit the profile, but they saw aspects of themselves in other tribes. One student, identified as a member of the Politically Disengaged Tribe, remarked that she "was honestly not shocked by this because I actually consider myself removed from the political scene," but as she read further she discovered that members of this tribe are "most likely to say that being White is necessary to be American and that people who hold other religious views are morally inferior," she was stunned, 


\section{Issues in Information Systems}

Volume 21, Issue 2, pp. 213-220, 2020

protesting, "I am clearly not White and my religious views are very similar to my political views" [liberal]. Another student wrote:

The tribe that the test said I belong in [is] politically disengaged, however I do have some of the qualities that fall under this category but there are other attributes such as detached, distrustful, and disengaged. These are the qualities that turn me away from this group because, I have formed my own strong opinions of every elective [sic] during the presidential campaign. However I do agree with a few things that are said in this article about the tribe because, whether it has something to do with age or maturity, the young generations seems [sic] to have less to little care for politicians that are selected because they think it will not affect them directly and it always does in the long run. I honestly believe that I should be a part of the Moderates, because I see myself engaged within politics and knowing that my vote counts no matter what.

Four of the Politically Disengaged Tribe said that they felt they should be more engaged. One observed:

Shying away from politics is not something I am proud of. I believe that if I have a problem with the rules and regulations for today's society then I need to do my part of educating myself. Then once I am educated I can fully engage with the politicians. "They are the least well-informed group on all measures of political knowledge." This may be true, but I am working on getting better. I believe that the more I brush up on my political knowledge the more I can help the world out. I stated in the survey the world is dangerous, the more dangerous it gets I believe I need to be prepared. This was actually an eye opening survey I am glad I took it.

One student agreed that he should pay more attention to politics, then noted to another student: "I like how you showed that you could find yourself in multiple tribes because I don't think that every person is in one set category. Many people have qualities and characteristics that can fit across multiple tribes. I think that is what is different about people today, and the fact that we are so different and dynamic than people in older generations."

\section{CONCLUSION}

This project started because of my negative experiences with my student, Bob, in a class in Fall 2019. Bob apparently disrupted a number of classes that fall, and was eventually expelled from the university. I wondered how he got his information and how he had been moving in the direction of becoming a White Supremacist, so I started reading about digital tribes. I wondered what my other students were reading online and which groups they might identify with, so I decided to have them do the surveys, which I also completed, sharing my results with the Spring 2020 Leadership and Popular Culture class. Bracketing the courses with these surveys seems to have been fruitful for a number of reasons.

First, the first survey allowed for students to introduce themselves to the class. I like to have some kind of exercise where students are able to talk briefly about their worldviews, because it's important for them to be heard and important for me to say, "Thanks for sharing who you are and what you believe. Welcome to this class."

Second, both surveys pointed up the diversity in the class, not just gender, race or social and economic class differences, but the diversity of values and norms among students. These different values were reflected in varying student lifestyles and political interests and orientations.

Third, the surveys provided an early and late opportunity for students to talk about themselves and their lives, which seemed increasingly important as we migrated online and began to practice social distancing. A number of students went back to homes where there was no computer and had to complete their courses on smart phones. There's another study here on the Digital Divide and how the Pandemic laid bare the haves and have nots.

Fourth, the surveys provided students with a deeper self-awareness and this is never a bad thing, at least for me. I realize that my background is in the humanities so I naturally gravitate toward helping students figure out who they are and how they fit into the larger scheme of things, but I think professors teaching more technical courses might help students in this life-long endeavor as well. 
Fifth, students who were politically disengaged may have started thinking about how important it is to be politically aware and active, especially in a presidential election year, and I didn't have to shame them into action, because the second survey prompted them to think about their political stances, in some cases their disengagement and distaste for politics, and ostensibly a resolve to be more involved in 2020.

Sixth, it provided a heads-up for me after the experience with my budding White Supremacist student in Fall 2019, which was, quite frankly, unnerving. I feel safer in a classroom knowing something about the students' worldviews and I think the students feel the same. They identify more with some students but are aware of the others' positions and orientations and this is important for success in the university and beyond.

Seventh, the ostensible existence of online tribes, whether sorted by lifestyle, political leaning, or engagement with the IoT, should encourage educators, politicians, marketers and businesses to pay attention to people's preferences and affiliations, because these digital and virtual connections will have an impact on students' worldviews expressed in the classroom, participation or non-participation in politics, and future purchases of everything from groceries to smart devices connected to the IoT.

\section{REFERENCES}

Burlacu, M. (2014). Digital anthropology: Theoretical perspectives regarding electronic tribes. Bulletin of the Transilvania University of Braşov, 7 (56), 241-248.

Cooper. B. (2017). Identifying the millennial tribes. Retrieved: https://www.retailcustomerexperience.com/blogs/identifying-the-millennial-tribes/

Hawkins, S., Yudkin, D., Juan-Torres, M., \& Dixon, T. (2018). Hidden tribes: A study of America's polarized landscape. New York, NY: More in Common.

Hockly, N. (2011). Digital tribes. Retrieved: http://www.emoderationskills.com/digital-tribes/

Siow, E., Tiropanis, T. \& Hall, W. (2018). Analytics of the Internet of Things: A survey. ACM Computing Surveys 51, 4, Article 74, 1-36.

Zollo, F. et al. (2017). Debunking in a world of tribes. PLOS ONE. Retrieved: https://doi.org/10.1371/journal.pone.0181821 